\title{
O problema do erro (pseûdos), a possibilidade do discurso predicativo e a questão ontológica no Sofista de Platão
}

The problem of error (pseûdos), the possibility of the predicative discourse and the ontological question on Plato's sophist

\section{Rodrigo César Floriano ${ }^{1}$ \\ José Henrique Fonseca Franco ${ }^{2}$ \\ Richard Romeiro Oliveira $^{3}$}

1 Graduado em História pela Universidade do Vale do Sapucaí (2013-2016), e graduando em Filosofia pela Universidade Federal de São João del Rei.

E-mail: rodrigocfloriano@gmail.com Orcid: http://orcid.org/0000-0002-8286-7323

2 Graduado em Engenharia Elétrica pela Universidade Federal de Itajubá. Iniciou Licenciatura em Filosofia na Universidade Federal de São João delRei. Iniciou no segundo semestre de 2019 Mestrado na linha de Metafísica e Filosofia da Mente na Universidade Federal de São João del-Rei.

E-mail: henriquefrancophi@gmail.com Orcid: http://orcid.org/0000-0003-2409-1384

3 Mestre e Doutor em Filosofia pela UFMG. Professor Adjunto do Departamento de Filosofia e Métodos da UFSJ.

E-mail: richardromeiro@hotmail.com Orcid: http://orcid.org/0000-0001-9776-1006

RESUMO: O presente artigo analisa as relações entre discurso e ser, estabelecidas de maneira dialética por Platão em seu diálogo tardio Sofista. Como se sabe, os sofistas defendiam a impossibilidade de provar a falsidade ou verdade de qualquer discurso. Tais pensadores basearam-se no interdito ontológico de Parmênides de Eleia, que asseverava a existência de uma correspondência estrita entre dizer e ser, de modo que seria, portanto, impossível dizer algo que não é, isto é, um não-ser. Contrariamente a essa perspectiva e fazendo uso do método da "diaíresis" - no qual os seres são caracterizados por suas diferenças mais fundamentais -, o Sofista se desdobra revisitando e pondo à prova as teorias ontológicas de seu tempo, a fim de explorar uma nova maneira de pensar a relação entre os seres. Com isso, Platão garante a possibilidade de análise qualitativa do discurso predicativo e, consequentemente, define o erro (psê̂dos) como desarmonia entre dizer e ser. No intuito de levar a cabo tal empreendimento, o filósofo explica como ocorre o entrelaçamento entre ser e não ser em suas relações básicas, as quais são mediadas pelas seguintes categorias fundamentais: Ser, Mesmo, Outro, Movimento e Repouso. A partir disso, a dialética é finalmente constituída como a técnica correta de diferenciação dos predicados em suas possibilidades de comunicação com cada sujeito. Graças aos resultados filosóficos alcançados por meio desses procedimentos, desenvolveram-se novas reflexões que levaram Aristóteles a instrumentalizar a análise da linguagem.

Palavras-chave: Filosofia da linguagem. Platonismo. Ontologia.

ABSTRACT: The present paper analyzes the relations between discourse and being, established in a dialectical way by Plato in his late dialogue Sophist. As is well known, the sophists defended the impossibility of proving the falsehood or truth of any discourse. Such thinkers were based on the ontological interdict of Parmenides from Eleia, which asserted the existence of a strict correspondence between saying and being, so that it would be, thus, impossible to say something that is not, that is, a non-being. Contrary to this perspective and making use of the "diairesis" method - in which beings are characterized by their most fundamental differences -, the Sophist unfolds by revisiting and examining the ontological theories of its time, in order to explore a new way of thinking about the relationship between beings. Thanks to this, Plato assures 
the possibility of qualitative analysis of the predicative discourse and, consequently, defines the error (pseûdos) as disharmony between saying and being. To carry out such an undertaking, the philosopher explains how the intertwining between being and non-being occurs in their basic relationships, which are mediated by the following fundamental categories: Being, Same, Another, Motion and Rest. From this, dialectics is finally constituted as the correct technique of differentiation of predicates in their possibilities of communication with each subject. Due to the philosophical results achieved by these procedures, new reflections developed that led Aristotle to instrumentalize language analysis.

Keywords: Language philosophy, Platonism, Ontology.

\section{INTRODUÇÃO}

No Corpus Platonicum encontramos notória preocupação com o problema da verdade (aletheia), preocupação esta que se expressa na tentativa de compreender a relação entre o inteligível puro - Forma ou Ideia - e o conhecimento humano. Tal esforço engloba a esfera do discurso (lógos) e foi desenvolvido de forma especial por Platão na sua obra tardia Sofista.

Ora, para este controverso personagem intelectual que é o sofista, cuja definição figura no centro do diálogo mencionado, a relação discursiva e ontológica é algo inviável. Esse tipo de questionamento, como se sabe, tem uma origem parmenídica, e é por isso que se torna um objeto relevante de investigação para o presente trabalho analisar os entraves teóricos da ontologia de Parmênides, cuja autoridade protegia os sofistas, em choque com as concepções filosóficas de Platão. A pretensão deste último é refundar o conceito de ser, objetivando trazer a predicação e a dialética para a esfera do real, de forma a caracterizar qualitativamente o discurso.

Pois bem, para evidenciar essa relação correta entre os seres ideais e a linguagem, o que pode ser definido como a essência da dialética (VAZ, 2001, p.14), o Sofista apresenta uma metodologia que por si não admite a contradição como pertencente à esfera da verdade. Tal método é chamado diaíresis, e nele as divisões por diferenças visam ao encontro das notas específicas (eide) mais essenciais de cada ser, separando-os assim do que não são e formando uma rede de definições. (VEGETTI, 2012. p.215)

No Sofista, a dialética é representada pela diaíresis, método de definição que busca os gêneros em que cada coisa está incluída, apresentando suas determinações essenciais. Portanto, a possibilidade de transmitir as determinações essenciais dos seres através do discurso está na base de uma concepção de discurso filosófico. (SOUZA, 1997, p.91)

Vale a pena mencionar que, a partir da definição do sofista, é apresentada uma via capaz de pensar o filósofo. Este último, de fato, sabendo o que não é, pode, através da diaíresis, iniciar uma busca do que é essencialmente. Busca que, possivelmente, se completaria na obra Filósofo, nunca escrita por Platão. "O Sofista é um diálogo no qual Platão submete-se a um processo de autorreflexão enquanto filósofo: ao pensar a forma do outro, pelo viés da caça ao sofista, o filósofo determina-se com relação ao seu alter ego." (MARQUES, 2006, p.87.)

Deve-se ressaltar que, embora o método não seja carregado de juízos de valor, a obra os emprega de forma explicita. A oposição entre filósofo/dialética, de um lado, e sofista/sofistica, de outro, é mais que uma diferenciação de saberes: é relação complexa de natureza tanto metodológica quanto social, tendo em vista a participação desses grupos na constituição da pólis. De forma sutil, é feita a comparação do primeiro 
com o cão e do segundo com o lobo (SOFISTA $231 \mathrm{a}^{1}$ ), comparações que, em outro diálogo, a saber, na República, evidenciam um juízo acerca dos papeis desempenhados por eles na vida pública e do ideal proposto por Platão (CORNFORD,1936, p. 182).

Com isso, apontamos as distintas questões ontológicas, epistemológicas, sociais, identitárias, etc., que assombravam Platão na confecção desse curioso diálogo. Sendo as naturezas apontadas plurais e de concretude evidente, o filósofo demonstra sua própria importância e a do saber por ele produzido para a sociedade que analisa.

Para compreender tais questões, mas principalmente a possibilidade da falsidade no discurso, a fim de superar as limitações discursivas trazidas pela ontologia eleática, Platão organiza no Sofista um diálogo dividido em três grandes partes. A primeira delas apresenta-nos o método da diaíresis e a aporia em que o interdito de Parmênides mergulha os discursos predicativos. Num segundo momento, debatem-se as teorias ontológicas vigentes naquele tempo, para a formulação mais sólida possível de uma nova ontologia que apresentará o não-ser como alteridade e não como negação. Por fim, submete-se o sofista a essa nova visão do ser, segregando seu discurso do saber verdadeiro, para assim o caracterizar como produtor de uma nãofilosofia e, consequentemente, de um discurso falso.

\section{O PAI PROTETOR}

Pensando na disposição contextual e dramática do diálogo, observa-se que ele é uma continuidade da obra Teeteto, em que as personagens Sócrates e Teeteto encontram-se com Teodoro, que lhes apresenta o Estrangeiro não nomeado, vindo de Eleia. Juntos, esses homens se propõem a pensar nas diferenças entre o sofista, o político e o filósofo, mas acabam se empenhando em definir inicialmente o primeiro (SOFISTA, 216 a-c).

Teeteto é escolhido para se contrapor ao protagonismo do Estrangeiro, cuja figura representa o resultado dialético do eleatismo no pensamento platônico. Dito de outra maneira, o Estrangeiro representa a alteridade de Platão ao pensar o mundo com os olhos de Parmênides, mas sem perder sua própria identidade.

Quando o Estrangeiro de Eleia fala, é um certo Parmênides em Platão que fala; é seu eleatismo que busca encontrar-se, um eleatismo que, ao explicitar-se em um personagem e em um discurso, nega-se e se trai, transformando-se em platonismo. Platão reconhece que carrega Parmênides dentro de si, e o faz falar, mas enquanto personagem. (MARQUES, 2006, p.58)

Platão se propõe a tal atividade de reelaboração do pensamento de Parmênides, pois é justamente por meio da ontologia do renomado Eleata que os sofistas se defendiam de toda crítica acerca do saber onisciente que diziam possuir. "Estrangeiro: - É que, ao que creio, eles [os sofistas] parecem ter uma sabedoria pessoal sobre todos os assuntos que contradizem.” (SOFISTA, 233 c) Em sua pretensão de possuir uma ciência universal, os sofistas sentiam-se protegidos pelo Pai Parmênides, que, no seu célebre poema $D a$ natureza, afirmava a impossibilidade de se dizer ou indicar o que não é nos seguintes termos:

Vamos, vou dizer-te - e tu escuta e fixa o relato que ouviste - / quais os únicos caminhos de investigação que há para pensar:/ um que é, que não é para não ser;/ é caminho de confiança (pois acompanha a verdade); / o outro que não é, que tem de não ser, / esse te indico ser caminho em tudo ignoto, pois

${ }^{1}$ As citações foram feitas segundo a seguinte tradução: PLATÃO. Sofista. Tradução: Jorge Paleikat e João Cruz Costa. São Paulo: Abril Cultural, 1972. 
não poderás conhecer o que não é, não é possível, / nem mostra-lo. (DKB2)2

Segundo essas palavras, o ser, não podendo não ser, só pode ser dito tautologicamente, inviabilizando a possibilidade da predicação no discurso, pois toda predicação afirma algo sobre a relação entre dois termos distintos, externos à unidade, o que configuraria um não-ser no ser, contrariando, assim, o axioma ontológico do eleata (DKB7). Como explicita Wolff: “A ontologia [de Parmênides] é perfeita, porém ela não é, pois o ser (onto-) devorou o discurso (-logia) que poderia falar do ser. Todos os seres são um e não se pode dizer nada." (WOLFF, 1996, p.182).

Tal interdito era sagazmente utilizado pelos sofistas, reduzindo o discurso apenas a uma ferramenta de convencimento, não de enunciação da verdade. Com isso, não existe possibilidade de provar que um suposto saber é falso. "Que modo encontrar, na realidade, para dizer ou pensar que o falso é real, sem que, já ao proferi-lo, nos encontremos enredados na contradição?” questiona o Estrangeiro de Eleia a Teeteto. (SOFISTA, 236 e).

Se admitimos a possibilidade de dizer o falso, seja enquanto opinião, seja enquanto discurso falso, o próprio fato do julgamento falso implica que as coisas que não são são de certo modo: seremos obrigados a ligar o ser ao não ser, ligar o que é de algum modo ao que não é. (MARQUES, 2006, p.170)

Pois bem, a partir desse axioma podemos dizer que o saber do filósofo e o saber do sofista se confundem e navegam juntos nos mesmos mares, "pois o mesmo é pensar e ser." (DKB3). Concepção esta insatisfatória aos olhos de Platão, se nos lembramos de sua notória preocupação com a verdade e, portanto, com a possibilidade do conhecimento, o qual, no platonismo, possui um inequívoco valor normativo, uma vez que se configura não como um mero conjunto de proposições abstratas, mas como princípio capaz de influenciar e orientar a ação. "Ora, para Platão, a ciência das Ideias é a única norma de ação reta e seus juízos são também juízos de valor.” (VAZ 2001. p. 16). No curso do diálogo são formuladas cinco definições acerca dos sofistas, são elas: a) caçador interesseiro de jovens ricos; b) comerciante, no atacado, de ensinamentos relativos à virtude; c) pequeno comerciante varejista, de segunda-mão, dos mesmos ensinamentos; d) erístico e contestador mercenário; e) refutador e purificador de almas (SOFISTA, 222 a - 231 c). Porém, nenhuma dentre elas se mostra satisfatória em relação à natureza do pretenso sábio, afinal, sendo aparências plurais, não contêm uma essência que as una.

Estrangeiro: - Não crês, que, quando um homem se nos apresenta dotado de múltiplos misteres, ainda que para designa-lo, baste o nome de uma única arte, trata-se apenas de uma aparência, que não é uma aparência verdadeira, e que ela, evidentemente, só se impõe, a propósito de uma dada arte, por que não sabemos nela encontrar o centro em que todos esses misteres vêm unificar-se, ficando nós, dessa forma, obrigados a dar, a quem for assim dotado, vários nomes em lugar de um só? (SOFISTA, 232 a)

Ora, estes inúmeros misteres não podem ser tratados como falsos se o valor ontológico de ser e dizer ainda estiver acorrentado a Parmênides, como já mencionado. "Excluída a falsidade do discurso, toda a opinião é verdadeira, e nenhuma o é.” (VAZ 2001. p.22) Porém, tamanha vastidão de saberes joga o sofista diante de outro problema levantado pelo Estrangeiro, qual seja, "se é possível que um homem saiba tudo." (SOFISTA, 233 a) A negativa dessa pergunta é de uma solidez maior que as palavras do Eleata, algo evidente

\footnotetext{
2 As citações foram feitas segundo a seguinte tradução: PARMÊNIDES. Da natureza. Tradução J. T. Santos, notas e comentários. São Paulo: Loyola, 2002.
} 
na seguinte ironia: "Teeteto: - Se assim fosse, estrangeiro, nós seriamos felizes." 3 (SOFISTA, 233 a) A explicação desses inúmeros misteres só pode advir de uma arte de produzir imagens que parecem ser, mas que não são: a mimética. "O que define estes produtos miméticos que são as imagens é o fato de serem 'outros que’ e ao mesmo tempo 'semelhantes’ àquilo com relação a que são outros.” (MARQUES, 2006, p.145)

Estrangeiro: - Assim, o homem que se julgasse capaz, por uma única arte, de tudo produzir, como sabemos, não fabricaria, afinal, senão imitações e homônimos das realidades. Hábil, na sua técnica de pintar, ele poderá, exibindo de longe os seus desenhos, aos mais ingênuos meninos, dar-lhes a ilusão de que poderá criar a verdadeira realidade e tudo o que quiser fazer. (SOFISTA, 234 b)

Com isso, para que exista diferença entre a imagem mimética (semelhante) e o ser real, possibilitando na linguagem o discurso falso e a predicação verdadeira, é necessária a quebra do axioma de Parmênides (SOFISTA, 241e). Tarefa complexa e aparentemente parricida, uma vez que envolve o gesto de matar simbólica e filosoficamente aquele que Platão reconhece como um "pai” (Parmênides), mas que tem valor de resgate do ser no uso da linguagem, impedindo sua dissociação, como defendiam os sofistas. Segundo Vaz, trata-se, na verdade, de um falso parricídio, pois o que Platão faz no Sofista "visa salvar a verdade essencial da posição eleatica, a primazia da inteligência e do inteligível sobre a multiplicidade confusa do sensível." (VAZ, 2001. p.22.)

\section{TECENDO UM NOVO PARADIGMA}

Para refundar a ontologia de forma satisfatória, é necessário analisar as diversas teorias do ser, e dialeticamente encontrar uma síntese sólida, negando suas posições frágeis e mantendo sempre um exercício de novos debates ${ }^{4}$. Estas diversas teorias, segundo o Estrangeiro, foram construídas como fábulas, e apresentam inúmeras rachaduras, que precisam ser evidenciadas e sanadas. "Estrangeiro: - Ao meu ver, Parmênides e todos os que, com ele, empreenderam discernir e determinar o número e a natureza dos seres, assim fizeram sem preceder a uma análise cuidadosa." (SOFISTA,242 c)

As diferentes formas de compreender a natureza do ser, cuja analise se faz necessária, dizem respeito a doutrinas contemporâneas à obra, referentes à unidade (totalidade) ou pluralidade (multiplicidade) dos entes, a movimento ou repouso. Aspectos trabalhados individualmente e em conjunto no diálogo, reafirmando o aspecto diairético da obra.

Pois bem, a primeira das teorias do ser colocada à prova é a pluralista, na qual o ser é constituído por uma oposição, como, por exemplo, a oposição entre quente e frio. (SOFISTA, 243 d-e) Na medida em

\footnotetext{
${ }^{3}$ Para mais acerca da ironia platônica: OLIVEIRA, Richard Romeiro. Drama, Aporia e Ironia no Mênon de Platão. Nuntius Antiquus, Belo Horizonte, v. 13, n. 2, 2017, p. 75-96.

${ }^{4}$ Como explica Mario Vegetti, em diálogos anteriores ao Sofista o exercício dialético configura-se como um procedimento argumentativo baseado na técnica de "pôr à prova as hipóteses", tendo em vista a obtenção de uma hipótese irrefutável, que, como tal, poderia funcionar como uma "tese anipotética": "Del Fedón y de la República podemos inferir indicaciones precisas acerca del modo de llegar al conocimiento "dialéctico" de las ideas. Pongamos que se trate - como sucede justamente en la República- de comprender qué es "la justicia" en sí: la idea de "justo". Los interlocutores serán llamados a formular sus "hipótesis" sobre la cuestión. El filósofo que conduce el diálogo (en este caso, Sócrates) intentará ir refutando las hipótesis propuestas, mostrando por ejemplo que no son universalizables, es decir, extensibles a todos los casos en cuestión, o bien que entrañan consecuencias inaceptables o dependen de supuestos igualmente inadmisibles. La confrontación argumentativa, en el caso de que tenga éxito, habría de conducir finalmente a formular una tesis "irrefutable», o cuanto menos "más difícil de refutar" (Fedón, 85c), esto es, ya no hipotética (República, VI, 511b). El contenido de dicha tesis se puede expresar en un discurso concluyente (que es, por ejemplo, para la justicia, "hacer lo que corresponde a cada uno")." (VEGETTI, 2012. p. 183)
} 
que ambos os contrários são, eles se confundem no ser e, em última análise, formam uma unidade, deixando de ser uma realidade plural. Por outro lado, sendo o ser identificado apenas com um dos contrários, o outro contrário não poderia existir, uma vez que não teria mais parte no ser. E se o ser fosse um terceiro, diferente dos contrários, não se compreende como teria ligação com os outros dois. "Em qualquer das hipóteses se levanta uma contradição entre o ser como tal em sua unidade e o grupo de elementos com os quais é identificado." (VAZ,2001, p.23) Com isso, a doutrina dos pluralistas, se analisada minuciosamente, revela-se aporética. (MARQUES, 2006, p.182)

Em oposição a tal teoria encontra-se a doutrina unitarista ou monista, em que o ser é absolutamente uno e necessariamente deveria ter apenas um nome, com o qual se confunde, encontrando, aqui, seu primeiro entrave (SOFISTA, 244 d). "O primeiro argumento do Estrangeiro é que, se há apenas uma coisa real, é inconsistente dar dois nomes, 'real' e 'uno'." (CORNFORD, 1936, p.220) Assim sendo, tal dupla nomeação, em si, já é ruptura da unidade, ou nomeação do que não é. E para esta relação ser possível é necessário admitir a alteridade entre o nome e o nomeado.

Por outro lado, o monismo revela-se também inconsistente na relação com o Todo, pois se o Todo é constituído de partes, então é mais que uno, e o uno, necessariamente, não se encontra para além da unidade, como afirma o Estrangeiro: "Porque o verdadeiro Uno, corretamente definido, só pode ser absolutamente indivisível." (SOFISTA, 245 a). Por outro lado, se o uno não faz parte do Todo então falta ao Todo, ou "a si mesmo", nas palavras do Estrangeiro (SOFISTA, 245 c). Em suma, se firmarmos compromisso com o uno, negando o Todo, consequentemente negamos o próprio ser. "Tudo que veio a ser, veio a ser sob a forma de um todo". (SOFISTA, 245 d). Como explica Marques:

A crítica do Estrangeiro incide sobre o fato de que, nos monistas e em Parmênides em particular, os três termos (ser, um e todo) servem para designar uma única coisa, a coisa mesma. O Estrangeiro introduz a diferença onde só havia a identidade (eleata). Ele mostra que, para poder tornar compatíveis as relações entre esses três termos (assim como aquilo a que se referem) é preciso necessariamente supô-los como outros, uns com relação aos outros. (MARQUES, 2006, p.186)

Após a exposição das ideias unitaristas o diálogo toma de assalto os materialistas, chamados de "gigantes" e apegados ao mundo concreto ou corpóreo (SOFISTA, 246 a-b), e seus opositores, chamados de "amigos das Formas", apegados ao inteligível imaterial (SOFISTA, 246 b-c). Na relação com o primeiro grupo, a explanação leva em conta uma sequência de determinações acerca do ser e as controvérsias resultantes da negação do não-material. Partindo do corpo animado, encontra-se a alma no grupo dos seres; em seguida, a justiça ou injustiça, como presença real e imaterial, habitando a alma; por fim, ao admitir que a justiça é real e invisível aos olhos, admite-se o invisível como real, ou nega-se parte desse processo de forma arbitraria e insensata. (SOFISTA, 246 e-247 b)

Teeteto: - A esse propósito [dos corpos das realidades invisíveis], não se limitarão mais a uma única e mesma resposta. Segundo dizem, a alma é, certamente corpórea. Mas quanto à sabedoria e a todas as demais realidades a que se refere tua pergunta, o temor lhes impedirá de se atreverem tanto a negar-lhes, absolutamente, o ser, quanto a afirmar, categoricamente, que todas são corpos. (SOFISTA, 247 b-c)

Quanto aos chamados Amigos das Formas, existe, para eles, uma afinidade entre o ser verdadeiro e duas características ontológicas principais: a de ser idêntico a si mesmo e a de ser imutável. (SOFISTA 248

\footnotetext{
5 "The Stranger's first argument is that, if there is only one real thing it is inconsistent to give it two names, 'real' and "one'." (CORNFORD, 1936, p.220)
} 
a). Essas características separam o ser e o devir e negam sua dynamis ou potência de relação ${ }^{6}$ - "aquilo em que está presente o poder de exercer ou de se sofrer a ação, por menor que seja” (SOFISTA, 247 c). Porém, tal negação se mostra controversa, na medida em que o conhecimento do ser se configura como ação e a ação, como movimento. Sem esse movimento, nada pode ser conhecido, e o ser se torna inapreensível. "Mas esse movimento não afeta a realidade intrínseca das Ideias." (VAZ, 2001, p.31) Afinal, sem o repouso não haveria ser e tudo seria devir. (SOFISTA, 249 b-c). Vaz assim sintetiza o ganho filosófico obtido nessa parte da discussão do Sofista:

Assim, esta parte crítica da argumentação platônica termina com um ganho eminentemente positivo: o ser, como "totalidade", não se identifica nem com o movimento, nem com o repouso absoluto, mas inclui os dois. (...) Entretanto, a demonstração só será completa quando, uma vez quebrada a rígida imobilidade do ser eleático, aparecer o ponto preciso de inserção do não ser e do erro no discurso, e a ciência, com o seu objeto - o verdadeiro -, emergir radicalmente distinta na "arte da ilusão" do sofista. (VAZ, 2001, p.31)

Diante das aporias em que tais doutrinas se encontram, após a revisão crítica de Platão, pode-se extrair de cada uma delas algum elemento remanescente que ajudará a fundamentar a relação dos seres como alteridade. E tal relação é chave para encontrar na linguagem um meio correto de predicar, sendo nessa esfera o termo predicar um sinônimo de participar.

Um predicado, portanto, revela uma parte da constituição do ser de algo, ou seja, indica uma forma de que este algo participa. Podemos dizer, então, que a determinação própria de um ser é resultado de suas relações de participação em outros seres, relações estas que se traduzem discursivamente como predicação. (SOUZA,1997, p. 84)

De forma sucinta, de cada doutrina resultam os seguintes elementos (MARQUES, 2006, p. 192 195):

- Dualistas: a diferença do ser na relação deste com os princípios de todas as coisas, sendo impossível estes últimos serem inseparáveis;

- Monistas: a relação de alteridade estabelecida entre o ser e o nome, na impossibilidade de ambos serem o mesmo;

- Parmênides: a dupla relação uno e Todo, simultaneamente unida e separada;

- Materialistas: o poder do ser de exercer e sofrer ação, e assim de quebrar a barreira do imutável, concebendo, na comunhão com os Amigos das Formas, o conceito de potência de relação;

- Amigos das Formas: a capacidade da alma de entrelaçar o corpóreo ao inteligível através do conhecimento. Ou seja, para que a alma apreenda o ser, é preciso a realização de um movimento (ação de conhecer) cujo termo é o repouso (realidade das Ideias). Fundamenta-se assim a comunicação entre ser, movimento e repouso, de forma que os dois últimos não se misturem, mas continuem relacionados ao ser.

Como já mencionado e evidenciado, todos os elementos remanescentes caminham em comum acordo para o encontro da alteridade na relação entre os seres e, consequentemente, para o encontro da diferenciação de uns em relação aos outros, e até das distinções que lhes são constitutivas. "Uma coisa só pode ser determinada por um predicado se os predicados que estão em contraste com ele podem ser negados. Assim, se o discurso predicativo informa algo sobre uma coisa, ele o faz na medida em que informa

6 Para maiores detalhes acerca do conceito de dynamis, cf. VAZ, H. C. L. A dialética das ideias no Sofista. In idem, Ontologia e história. Escritos de Filosofia VI. São Paulo, Edições Loyola, 2001. p. 27-31. 
tanto o que a coisa é quanto o que a coisa não é." (SOUZA,1997, p. 86) Estas considerações se reafirmam na medida em que, descartando tanto a comunicação de todos os seres com todos os seres quanto a exclusão total entre eles, encontra-se na associação seletiva entre os seres a chave para sistematizar a predicação na linguagem.

Estrangeiro: - Desde que, pois, algumas vezes se consente a união, e outras vezes se recusa, o caso seria mais ou menos idêntico ao que se dá com as letras: entre elas também, com efeito, há desacordo entre algumas e acordo entre outras. (SOFISTA, 252 e - 253 a)

A partir desse ponto, cujo resultado é a constatação da comunicação dos seres de forma participativa ou seletiva, ${ }^{7}$ podemos dizer que a dialética tem, nas relações entre o discurso e o real, a mesma natureza da gramática ao analisar as letras na formação das palavras. Isto é, para o domínio da gramática, é necessário, em síntese, o correto uso das vogais - pois estas funcionam como laços entre as consoantes - permitindo, com isso, afirmar quais letras se harmonizam entre si e quais não. (SOFISTA, 253 a) E tais procedimentos, de reconhecimento, classificação e (se necessária) interdição, aproximam e assemelham as atividades supracitadas. Ao tratar da referida analogia Vegetti aponta a dialética como "gramática geral do ser, do pensamento e das possibilidades correspondentes de enunciação." (VEGETTI, 2012. p. 221)

Ora, na área da predicação verdadeira, é o filósofo que tem esse protagonismo, graças sobretudo à ciência dialética. "Estrangeiro: - Ora, esse dom, o dom dialético, não atribuirás a nenhum outro, acredito, senão àquele que filosofa em toda pureza e justiça." (SOFISTA, 253 e) Com isso, a ciência dialética pode ser vista como a ciência disposta a discriminar as devidas participações dos entes no ser. Como afirma o Estrangeiro no diálogo: "dividir assim por gêneros, e não tomar por outra, uma forma que é a mesma, nem pela mesma uma forma que é outra, não é essa, como diríamos, a obra da ciência dialética?” (SOFISTA, 253 d). ${ }^{9}$

$\mathrm{Na}$ articulação dos gêneros acima mencionados são apresentados, inicialmente, o próprio ser, o repouso e o movimento, sendo os dois últimos contrários e impossibilitados de se associarem entre si. "Estrangeiro: - Assim, cada um é outro com relação aos dois que restam, e o mesmo que ele próprio." (SOFISTA, 254 d)

Isso significa que temos, então, cinco gêneros supremos: ser, repouso, movimento, mesmo e outro. Repouso e movimento relacionam-se com o ser e com o mesmo, na medida em que cada um deles é (ou existe) e goza da identidade consigo mesmo; por outro lado, a diferença entre movimento e repouso está também assegurada, na medida em que a redução do movimento ao repouso ou, vice-versa, do repouso ao movimento geraria a já citada confusão entre os contrários. (SOFISTA, 255 a-b). Torna-se, dessa maneira, toda relação entre os gêneros uma dupla relação entre ser e não ser, isto é, entre um ser que é ele mesmo e um ser que é outro. (TAYLOR, 2001. p. 388-389).

Estrangeiro: - Então o movimento é o mesmo, e não é o mesmo: é necessário convir nesse ponto sem

\footnotetext{
7 "La seule solution acceptable est celle d'une communication et non-communication selectives des genres." (DIXSAUT, 2001, p. 152).

8 “(...) gramatica general del ser, del pensamento y de las correspondientes posibilidades de enunciacion," (VEGETTI, 2012. p. 221)

9 “Une science est donc necessaire pour 'cheminer' à travers les discours et montrer quells genres peuvent communiquer entre eux et quels ne le peuvent pas. Cette Science est sans aucun doute la science la plus importante, et l'Étranger lui donne alors son nom: c'est la dialectique (...) La science dialectique a son fondement dans l'existence d'identités et de differences et son exercice consiste à discerner les réelles des apparentes." (DIXSAUT, 2001, p. 154).
} 
nos afligirmos, pois, quando dizemos o mesmo e não o mesmo, não nos referimos às mesmas relações. Quando afirmamos que ele é o mesmo é porque, em si mesmo ele participa do mesmo, e quando dizemos que ele não é o mesmo, é em consequência de sua comunidade com "o outro", comunidade esta que o separa do "mesmo" e o torna não-mesmo, e sim outro; de sorte que, neste caso, temos o direito de chamá-lo "não-o-mesmo". (SOFISTA, 255 a-b)

Pois bem, o outro não está dissociado do mesmo de maneira análoga à relação de movimento e repouso, pois o mesmo necessita do outro para se caracterizar, e o outro se caracteriza sempre como um não- mesmo. (SOFISTA, 255 a). Ambos, o mesmo e o outro, são e encontram na diferença o que os singulariza.

Definidos esses cinco gêneros inconfundíveis (ser, movimento, repouso, mesmo e outro), a característica de serem outro em relação aos restantes aproxima a realidade do não-ser do discurso acerca do ser. Afinal, o outro em relação ao mesmo é um não ser o mesmo, o que permite determinar a diferença, e não a contrariedade, como o conceito que explica a relação entre ser e não ser.

Estrangeiro: - Não podemos, pois, admitir que a negação signifique contrariedade, mas apenas admitiremos nela alguma coisa de diferente. Eis o que significa o 'não' que colocamos como prefixo dos nomes que seguem a negação, ou ainda das coisas designadas por esses nomes. (SOFISTA,257 b-c)

Tais diferenças trazem, assim, equidade entre ser e não ser, pois todo não ser é tão ser quanto todos os outros seres. Por exemplo, o belo não é mais ser que o não belo. "Estrangeiro: - Assim, cada forma encerra uma multiplicidade de ser e uma quantidade infinita de não-ser.” (SOFISTA, 256 e). Ora, é justamente na quantidade finita e múltipla do ser que se encontra o discurso verdadeiro, assertivo entre o dizer de algo e seu ser real, em meio aos inúmeros não-seres existentes.

Na sequência do diálogo, Platão evidencia no discurso (logos) a presença de dois elementos fundamentais: um nome (ónoma), considerado o sujeito, a quem são atribuídos determinados verbos (rhémata), isto é, seus predicados "Estrangeiro: - Nomes apenas, enunciados de princípio a fim, jamais formam um discurso, assim como verbos enunciados sem o acompanhamento de algum nome." (SOFISTA, 262 a) E estes predicados, para serem verdadeiros, devem estar alinhados e ajustados à realidade ou natureza do sujeito. (VEGETTI, 2012, p. 219) Em analogia, podemos considerar que dizer o verdadeiro ser é um desafio semelhante ao do homérico Ulisses, ao acertar uma flecha entre os orifícios dos machados dispostos em seu palácio, no momento anterior à matança dos pretensos usurpadores de seu trono. ${ }^{10}$

\section{O SOFISTA EM PROVA}

Segundo os conceitos platônicos até aqui apresentados, quando se determina o ser, surgem os contornos do não ser. Da mesma forma, ao delimitarmos o discurso verdadeiro, discriminamos o falso, em desafeto com o ser de quem se pretendeu discorrer. Com isso, finalmente, é possível apontar um parâmetro qualitativo de julgamento das artes sofísticas.

Estrangeiro: - Assim, o conjunto formado de verbos e de nomes, que enuncia, a teu respeito, o outro como sendo o mesmo, e o que não é como sendo, eis, exatamente, ao que parece, a espécie de conjunto

10 "[Ulisses] tomou uma flecha que estava sobre a mesa, ao lado, fora do carcás; dentro deste ficaram as outras, que em breve os Aqueus iriam provar; colocou-a na curvatura do arco, puxou a si as cordas e os entalhes e dali, donde estava sentado, disparou a flecha, de ponta de bronze, a qual, sem se desviar, atravessou o orifício de todos os machados, indo sair na extremidade oposta." (HOMERO, 1979, p. 196) 
que constitui, real e verdadeiramente, um discurso falso. (SOFISTA, 263 d)

Para delimitar o sofista como portador de tal falsidade, são feitas outras divisões: 1) a bipartição da arte de produzir, que separa uma arte que produz coisas reais de outra, que produz imagens irreais (miméticas) (SOFISTA, 265 a-b); 2) a bipartição dos produtores em divinos e humanos, sendo as produções divinas e reais compostas, por exemplo, de animais e plantas (SOFISTA, 266 b), e as divinas e irreais, de sonhos e sombras, do fogo ou do sol. (SOFISTA 266 b-c). Já as produções humanas podem ser reais, quando concretas (uma casa, por exemplo), ou falsas, chamadas de simulacros, como uma pintura da casa (SOFISTA, $266 \mathrm{c})$.

Entretanto, a arte do simulacro se divide na produzida por instrumentos (tintas ou arpas), e na produzida pela pessoa que se faz a si mesma de instrumento, sendo o sofista alguém que pratica uma arte deste último tipo, por fazer das próprias palavras o canal de sua ação. (SOFISTA, 267 a)

Outra divisão se encontra entre os imitadores conscientes da realidade, que imitam como um ator se fazendo de cão ou gato, e os imitadores ignorantes do objeto da imitação, como os falsos virtuosos.

Estrangeiro: - Mas que dizer da figura da justiça, e, em geral, de toda virtude? Não haverá muitos que, sem a conhecer, mas dela tendo apenas uma opinião qualquer, se desdobram em todas as suas forças e zelo, para faze-la aparecer como uma qualidade pessoal realmente neles presente, imitando-a o mais que podem em seus atos e palavras? (SOFISTA, $267 \mathrm{c}$ )

Com isso, aqueles que se baseiam nas opiniões para fundamentar seu saber são chamados doxomiméticos, enquanto os que se baseiam na imitação da ciência são miméticos sábios. "Estrangeiro: - (...) à imitação que se apoia na opinião daremos o nome de doxomimética; e à que se apoia na ciência, o nome de mimética sábio." (SOFISTA, 267 d-e). De tal associação entre os doxomiméticos e a ignorância do que é imitado nasce o ingênuo, fiel que guarda ciência em meio às suas ilusões. Porquanto o doxomimético, ciente do não saber, se apresenta como sábio, mas o faz de forma irônica. (SOFISTA 267 e- 268 a) Sendo o sofista um irônico, resta estabelecer que sua arte funciona apenas em discussões particulares e baseadas em argumentos breves, enquanto que o orador popular é capaz de praticar tais ironias em eventos públicos, dispondo de longos e articulados discursos. (SOFISTA, 268 b)

Após tal sequência de divisões, visando à determinação da essência do sofista, foi possível caracterizá-lo de forma inconfundível. Ao fim da discussão, o sofista é definido, pois, como um produtor consciente e irônico de falsas virtudes, capaz apenas de contradizer algum interlocutor, nunca sendo capaz de criar discursos verdadeiros, pois se fundamenta necessariamente na opinião (doxa). Com isso, Platão exila os sofistas de forma definitiva no limbo que se encontra aquém do saber.

Dessa forma, ao final do diálogo, o objetivo do filósofo de discutir as ideias do Pai Parmênides tem um saldo positivo, trazendo à tona uma nova concepção de ser e uma definitiva definição de sofista. Além disso, por meio da definição do sofista, uma potencial definição do filósofo também pode ser vislumbrada, aprofundando o debate acerca da natureza das Ideias, conteúdo principal do saber do Filósofo.

\section{CONCLUSÃO}

Após a análise minuciosa do percurso argumentativo desenvolvido no Sofista, é cabível estabelecer alguns pontos acerca da obra e dos objetivos traçados pela presente pesquisa. Visamos, com isso, efetuar uma explanação geral que recapitule os pontos essenciais trabalhados, sem encerrar suas possibilidades de 
debate.

Inicialmente, é valido ressaltar a importância deste diálogo para os estudos referentes à forma e à estrutura da linguagem, uma vez que, a partir de uma consistente abordagem dialética, ele iniciou uma busca por maneiras mais precisas de compreender o funcionamento do discurso. Após um processo de desontologização, tais preocupações culminaram com a fundação da Lógica pelo mais notório discípulo da Academia, Aristóteles. "Após o Sofista, a ontologia dos cinco gêneros platônicos dá lugar, com efeito, à lógica das categorias aristotélicas. Mas, com o tratado das Categorias, a via categorial pode terminar e a ontologia pode tornar-se definitivamente uma lógica.” (WOLFF, 1996, p.221)

Isso nos permite, assim, apontar as preocupações com o correto uso da linguagem, das quais o Sofista constitui uma expressão privilegiada, como acompanhantes do pensamento filosófico desde suas mais longínquas origens, com Parmênides, no século VI a. C., perpassando, a partir desses primórdios, as obras de todos os grandes filósofos e não perdendo sua atualidade até o presente momento.

Faz- se necessário também ressaltar a organização interna do diálogo, que apresenta metodologia sagaz, ao reunir para a formulação de argumentos sólidos a maior variedade de pontos acerca do principal objeto analisado (neste caso, o ser e as doutrinas sobre ele formuladas). Ainda acerca desse ponto é válido também discriminar a importância da obra para entender melhor a questão das Formas inteligíveis, a qual tem centralidade para o pensamento platônico, encontrando-se intimamente vinculada à concepção de dialética desenvolvida pelo platonismo. "A unidade que a Ideia do Ser confere à dialética, segundo o Sofista, é exatamente a unidade que cada proposição verdadeira possui e que a distingue do erro.” (VAZ, 2001, p.49).

Em suma, o Sofista resgata o ser da solidão eleática, permitindo que a identidade - prezada por Parmênides - permaneça, mas em coexistência com a diferença e a alteridade. Tal relação, complexa e heterogênea, permite o ser predicar-se de elementos diversos, mas de forma rigorosa, numa ligação necessariamente verdadeira com o que é real. A possibilidade do discurso falso é explicada e o sofista tem seus inúmeros misteres separados do objeto propriamente dialético do filósofo.

\section{REFERÊNCIAS}

CORNFORD, F. M. (1935). Plato's Theory of Knowledge. The Theaetetus and the Sophist of Plato translated with a running commentary. London: Routledge \& Keegan Paul, 1935.

DIXSAUT, M. (2001) Métamorphoses de la dialectique dans les dialogues de Platon. Paris: Vrin, 2001.

HOMERO. Odisseia. Tradução de Antônio Pinto de Carvalho. - São Paulo: Abril Cultural, 1979.

MARQUES, M. P. (2006) Platão, pensador da diferença. Belo Horizonte: Editora UFMG, 2006.

OLIVEIRA, Richard Romeiro. (2017) Drama, Aporia e Ironia no Mênon de Platão. Nuntius Antiquus, Belo Horizonte, v. 13, n. 2, p. 75-96.

PLATÃO. Sofista. Tradução: Jorge Paleikat e João Cruz Costa. São Paulo: Abril Cultural, 1972.

PARMÊNIDES. Da natureza. Tradução J. T. Santos, notas e comentários. São Paulo: Loyola, 2002.

REALE, Giovanni. (1974) Introdução a Aristóteles. Tradução: Artur Morão. Edições 70 - Lisboa /

11 A maneira como a lógica foi desenvolvida pelo Estagirita como instrumento formal de análise argumentativa se encontra no conjunto de suas obras nomeado Órganon. Para o início de tal discussão, cf. REALE, Giovanni. Introdução a Aristóteles. Tradução: Artur Morão. Edições 70 - Lisboa / Portugal. 1997. p. 115-134. 
Portugal. 1997.

SOUZA, E. C. de. (1997) Sobre a teoria da participação das formas no Sofista de Platão. Hypnos 3 p.81-88.

TAYLOR, A. E. (1926) Plato. The Man and his Work. Mineola: Dover Publications, 2001.

VAZ, H. C. L. (1968) A dialética das ideias no Sofista. In idem, Ontologia e história. Escritos de Filosofia VI. São Paulo, Edições Loyola. p. 13-55. 2001.

VEGETTI, M. (2003) Quince lecciones sobre Platón. Traducción de Miguel Salazar. Madrid: Gredos, 2012.

WOLFF, F. (1996) Dois destinos possíveis da ontologia: a via categorial e a via física. Analytica, volume 1, número 3, p. 179-225.

Artigo recebido em: 23 de abril de 2020

Artigo aceito em: 01 de julho de 2020 